\title{
STANDAR KOMPETENSI TUTOR PENDIDIKAN KEAKSARAAN: REFLEKSI DARI PENGEMBANGAN MODEL DI JAYAGIRI
}

\author{
Ade Kusmiadi*
}

\begin{abstract}
State rules No. 19, 2005 on National Education Standards has defined eight criteria as a reference in developing education in all areas. One criterion is regarding standards on educators and educational personnel. The term educators may refer to teachers, instructors, and tutors. The later is applied to literacy education area in NFE. Tutors are to have background on pedagogy, good personality, good social relationships and be professional. These competencies are of minimum requirements. The article discusses a model on tutor's competencies which reflect their expected performances, and their supporting subcomponents as well as attached elements.
\end{abstract}

Keywords: national education standards, tutors, literacy education, competencies.

\section{PENDAHULUAN}

Pendidikan pada dasarnya diselenggarakan dalam rangka membebaskan manusia dari berbagai persoalan hidup dan kehidupan yang melingkupinya. Dalam konteks pendidikan keaksaraan, berarti bagaimana memberaksarakan penduduk dari kebutaaksaraan agar dapat membaca dunia kehidupannya. Dahulu orang yang kita yakini sebagai orang buta aksara, ternyata dapat melakukan hal-hal seperti di atas, baik melalui musik, drama, lagu, adat istiadat, pola pakaian, hikayat, sejarah, dan sebagainya. Hal-hal tersebut ternyata pula telah dilakukan dengan pola terstruktur yang membantu mereka mengingat dan berkomunikasi dengan sesamanya, bahkan dengan perbedaan ruang dan waktu sekalipun.

Orang yang buta aksara bisa jadi mempunyai pengetahuan yang luas. Contoh, orang di pedalaman ternyata sudah mempunyai pengetahuan yang kompleks mengenai cara bertanam, memelihara berbagai hewan ternak, membangun rumah, dan membuat berbagai macam kerajinan. Mereka menguasai pendidikan dasar yang diperlukan untuk bertahan hidup, bahkan dalam kondisi yang sangat sulit sekalipun.

Pengetahuan keaksaraan dalam pendidikan formal tidak terlalu diperlukan oleh mereka yang tinggal di wilayah pedesaan seperti gambaran di atas. Banyak orang bisa bertahan hidup tanpa pendidikan keaksaraan dan mereka mampu membuat strategi yang efektif untuk menyikapi hal-hal yang berkaitan dengan kegiatan membaca dan menulis. Saat mereka harus melakukan hal-hal yang berkaitan dengan baca tulis hitung

* Pamong Belajar BPPLSP Regional Il Jayagiri misalnya, mereka meminta bantuan orang lain atau menggunakan jasa para ahli (orang yang sudah melek aksara). Tetapi yang pasti bahwa, kehidupan akan terus berubah dan prospek perubahan ke depan jauh seperti yang dibayangkan. Oleh karena itu, sangat kecil kemungkinannya di suatu tempat tidak memerlukan pentingnya pendidikan keaksaraan untuk sebuah perubahan. Ke depan kebutuhan baca tulis hitung menjadi penting bahkan untuk mereka yang buta aksara sekalipun.

UNESCO mendefinisikan kemampuan keaksaraan atau melek aksara sebagai kemampuan seseorang untuk membaca dan menulis kalimat sederhana yang diperlukan dalam kehidupan seharihari, dan seseorang dikatakan mempunyai kemampuan keaksaraan fungsional jika seseorang tersebut dapat terlibat dalam aktivitas dan kemampuan keaksaraan merupakan prasyarat sebagai effective function kelompok dan sebagai dasar bagi dirinya untuk meningkatkan kemampuan membaca, menulis, dan berhitungnya sendiri.

Tujuan penyelenggaraan kelompok belajar keaksaraan adalah membantu peserta didik mencari dan menggunakan bahan calistung sendiri. Karena itu, tutor tidak hanya membantu peserta didik membaca buku, tetapi tutor juga membantu mereka pergi ke Taman Bacaan Masyarakat (TBM). Tutor tidak hanya membantu peserta didik membaca informasi tentang bagaimana memperoleh dana, tutor juga membantu mereka pergi ke koperasi atau bank untuk mencari informasi dan formulir atau membantu peserta didik membuka rekening. Tutor juga meminta nara sumber dari instansi lain untuk membantu peserta didik. 


\section{PEMBAHASAN}

\section{Tutor sebagai Pendidik}

Pendidik, menurut Mulyasa (2005:13), memegang peranan yang sangat penting dalam perencanaan maupun dalam pelaksanaan kurikulum. Simon dan Alexander (1980) telah merangkum lebih dari 10 hasil penelitian di negara-negara berkembang dan menunjukkan adanya dua kunci penting dari peran pendidik yang berpengaruh terhadap peningkatan prestasi belajar peserta didik, yaitu jumlah waktu efektif yang digunakan pendidik untuk pembelajaran di kelas dan kualitas kemampuan pendidik.

Pengembangan kualitas pendidik merupakan suatu proses yang kompleks dan melibatkan berbagai faktor yang saling terkait. Oleh karena itu, dalam pelaksanaannya tidak hanya menuntut keterampilan teknis para ahli terhadap pengembangan kompetensi pendidik, tetapi harus pula dipahami berbagai faktor yang mempengaruhinya. Sehubungan dengan itu, perlu dilakukan berbagai strategi dan cara untuk meningkatkan kualitas pendidik dalam mengembangkan berbagai aspek pendidikan dan pembelajaran, sehingga pendidik memiliki kompetensi pedagogi, sosial, kepribadian, dan profesional.

Peraturan Pemerintah No. 19 Tahun 2005 tentang Standar Pendidikan Nasional telah mengamanatkan 8 (delapan) standar yang harus menjadi patokan dalam pengembangan pendidikan. Delapan patokan tersebut meliputi: (1) Standar Isi, (2) Standar Proses, (3) Standar Kompetensi Lulusan, (4) Standar Pendidik dan Tenaga Kependidikan, (5) Standar Sarana dan Prasarana, (6) Standar Pengelolaan, (7) Standar Pembiayaan, dan (8) Standar Penilaian Pendidikan.

Komponen pendidik dan tenaga kependidikan secara eksplisit dinyatakan pada Pasal 28 ayat 1 , bahwa pendidik harus memiliki kualifikasi akademik dan kompetensi sebagai agen pembelajaran, sehat jasmani dan rohani serta memiliki kemampuan untuk mewujudkan tujuan pendidikan nasional.

Kualifikasi akademik sebagaimana dimaksud adalah tingkat pendidikan minimal yang harus dipenuhi oleh seorang pendidik yang dibuktikan dengan ijazah dan/atau sertifikat keahlian yang relevan, sedangkan kompetensi sebagai agen pembelajaran terdiri atas kompetensi pedagogik, kompetensi kepribadian, kompetensi profesional, dan kompetensi sosial.

Pendidik, berdasarkan UU Sisdiknas No. 20 Tahun 2003, Pasal 1 ayat 6 , adalah tenaga kependidikan yang berkualifikasi sebagai guru, dosen, konselor, pamong belajar, widyaiswara, tutor, instruktur, fasilitator, dan sebutan lain yang sesuai dengan kekhususannya, serta berpartisipasi dalam penyelenggaraan pendidikan.

Merujuk pada PP No. 19 Tahun 2005, seorang tutor pendidikan keaksaraan idealnya memiliki kualifikasi akademik dan kompetensi yang sesuai dengan standar yang telah ditetapkan, melalui penguatan kompetensi dan sertifikasi oleh lembaga pendidikan yang terakreditasi atau lembaga sertifikasi mandiri yang dibentuk oleh organisasi profesi yang diakui pemerintah.

Kompetensi tutor pendidikan keaksaraan intinya berkenaan dengan kompetensi dalam memberikan bantuan belajar kepada peserta didik dalam proses pembelajaran mandiri atau proses pembelajaran dalam kelompok pada program pendidikan keaksaraan, baik untuk pendidikan keaksaraan tingkat dasar, tingkat lanjut, atau tingkat mandiri.

\section{Hakikat Kompetensi}

Kamus Webster College Dictionary menjelaskan makna 'competence', sebagai: "sufficient means for one needs condition or quality of being competent; ability; fitness; specific legal capability, power, or jurisdiction." Kutipan dari kamus itu dapat diartikan bahwa kompetensi merupakan kebutuhan yang tercukupi pada suatu kondisi dengan kualitas yang kompeten, mampu, sesuai, memiliki kapabilitas khusus secara sah, memiliki kekuatan atau kemampuan hukum tertentu.

Kompetensi dapat pula didefinisikan sebagai sekumpulan pengetahuan, keterampilan, sikap, dan nilai sebagai kinerja yang berpengaruh terhadap peran, perbuatan, prestasi, dan pekerjaan seseorang. Dengan demikian, kompetensi dapat diukur dengan standar umum serta dapat ditingkatkan melalui pendidikan dan pelatihan.

Artinya, untuk dapat menyelesaikan suatu tugas atau profesinya dengan baik, seseorang harus memiliki hal-hal sebagai berikut.

1. Pengetahuan tentang tugas yang akan dikerjakan dan bagaimana mengerjakan tugas tersebut.

2. Keterampilan yang dibutuhkan untuk mengerjakan tugas tersebut.

3. Sikap kerja yang dibutuhkan untuk dapat mengerjakan tugas dengan baik.

4. Sumber daya fisik yang cukup untuk dapat melaksanakan tugas dimaksud.

Spencer dan Spencer (1993: 9-11) membahas lima tipe kompetensi berikut. 
1. Motif. Sesuatu yang dimiliki seseorang untuk berpikir secara konsisten atau keinginan untuk melakukan suatu aksi. Contoh: seseorang yang mempunyai motivasi akan menentukan tantangan untuk dirinya sendiri, kemudian bertanggung jawab untuk mencapai tantangan tersebut dan menggunakan balikan untuk memperbaikinya. Motif bekerja secara intrinsik atau mulai dengan sendirinya (self-starting). Motif menguasai pembawaan yang dapat memperkirakan apa yang dikerjakan seseorang dalam jangka panjang tanpa pengawasan yang ketat.

2. Pembawaan. Karakteristik fisik yang merespon secara konsisten berbagai situasi dan informasi. Contoh: reaksi terhadap waktu dan sudut pandang yang baik adalah kompetensi bawaan seorang pilot pesawat tempur. Kontrol emosi diri dan inisiatif merupakan respon konsisten yang lebih kompleks. Kompetensi bawaan yang dapat mengontrol emosi dan menumbuhkan inisiatif merupakan kompetensi seorang manajer yang berhasil.

3. Konsep diri. Tingkah laku, nilai, atau citraan (image) seseorang. Contoh: percaya diri. Seseorang yang percaya diri akan efektif pada berbagai situasi. Rasa percaya diri ini sudah menjadi bagian dari jati dirinya, sehingga dapat diterapkan dalam berbagai situasi yang berbeda.

4. Pengetahuan. Informasi khusus yang dimiliki seseorang. Contoh: ahli bedah memiliki pengetahuan mengenai saraf dan tulang pada tubuh manusia. Menurut Spencer (1993) pengetahuan merupakan kompetensi yang kompleks. Hasil tes pengetahuan sering salah dalam memperkirakan kinerja seseorang. Tes pengetahuan sering gagal mengukur pengetahuan dan keterampilan yang digunakan dalam bekerja. Hal ini disebabkan karena hal-hal berikut.

a. Tes yang digunakan untuk mengukur ingatan seseorang, padahal yang diperlukan adalah kemampuan mencari pengetahuan.

b. Tes pengetahuan mengukur respon seseorang terhadap pilihan-pilihan jawaban bukan apakah tindakannya dalam menggunakan pengetahuan tersebut. Kemampuan memilih pilihan jawaban yang benar sangat berbeda dengan kemampuan menentuan keberpihakan terhadap situasi konflik atau kemampuan memberikan argumen untuk diterima. Pengetahuan meramalkan apa yang dapat dikerjakan seseorang, bukan pada apa yang akan dikerjakan setelah tes.

5. Keterampilan. Kemampuan untuk melakukan tugas secara fisik atau mental. Contoh, dokter gigi memiliki kemampuan menambal gigi tanpa merusak saraf. Programer komputer memiliki kemampuan untuk mengorganisasi 50.000 barisan kode dengan perintah yang berurutan.

Dapat disimpulkan bahwa standar kompetensi tidak berarti hanya kemampuan menyelesaikan suatu tugas, tetapi dilandasi pula bagaimana dan mengapa tugas itu dikerjakan. Dengan kata lain standar kompetensi meliputi faktor-faktor yang mendukung seperti pengetahuan dan kemampuan untuk mengerjakan suatu tugas dalam kondisi normal di tempat kerja serta kemampuan mentransfer dan menerapkan kemampuan dan pengetahuan pada situasi dan lingkungan yang berbeda. Berdasarkan uraian di atas, kompetensi meliputi hal-hal sebagai mana terlihat dalam tabel berikut.

Tabel 1. Komponen kompetensi

\begin{tabular}{|c|c|}
\hline KETERAMPILAN TUGAS & $\begin{array}{c}\text { Unjuk kerja yang dipersyaratkan untuk } \\
\text { menyelesaikan suatu tugas. }\end{array}$ \\
\hline KETERAMPILAN MENGATUR TUGAS & $\begin{array}{c}\text { Kemampuan mengatur/mengorganisasi } \\
\text { tugas-tugas yang berbeda dalam suatu } \\
\text { pekerjaan. }\end{array}$ \\
\hline $\begin{array}{c}\text { KETERAMPILAN MENGATASI KEADAAN } \\
\text { TAK TERDUGA }\end{array}$ & $\begin{array}{c}\text { Kemampuan untuk menyelesaikan masalah } \\
\text { atau pekerjaan yang berbeda dengan } \\
\text { pekerjaan yang biasa dilakukan. }\end{array}$ \\
\hline KETERAMPILAN BERADAPTASI & $\begin{array}{c}\text { Kemampuan yang dibutuhkan untuk } \\
\text { beradaptasi dengan lingkungan kerja dan } \\
\text { bekerja dengan orang lain. }\end{array}$ \\
\hline
\end{tabular}




\section{Penyusunan Kompetensi}

Pengembangan standar kompetensi merupakan proses yang sangat penting. Penyajian kompetensi yang baik harus dapat mengubah kecakapan berpikir, bekerja, dan prestasi seseorang. Dalam penyusunan standar kompetensi, elemen kompetensi, dan kriteria unjuk kerja yang harus dimiliki tutor perlu ada perubahan penekanan pola pikir dan pola tindak.

Beberapa prinsip dalam pengembangan kompetensi adalah sebagai berikut.

1. Meluas (broad), sehingga tutor memperoleh kesempatan yang luas untuk mengembangkan pengalaman tentang pengetahuan, keterampilan, sikap, dan nilai berkaitan dengan etika, estetika, logika, serta kinestetika saat mengajar.

2. Seimbang (balanced), dalam arti setiap kompetensi perlu dimiliki melalui program penguataan secara seimbang agar diperoleh kepemilikan kompetensi yang seimbang.

3. Relevan, yaitu setiap kompetensi terkait dengan peran tutor sebagai pendidik yang memiliki tugas meningkatkan mutu kehidupan peserta didik (PD) melalui bantuan belajar yang diberikannya dalam proses pembelajaran mandiri atau proses pembelajaran dalam kelompok pada program pendidikan keaksaraan.

4. Perbedaan (differentiated), merupakan upaya pelayanan individual di mana tutor perlu memahami: apa yang harus diajarkan, strategi, metodologi, bagaimana memahami orang dewasa, atau bagaimana berbuat untuk mengembangkan PD secara optimal.

Penyusunan kompetensi tentunya tidak dapat dilakukan sekali jadi. Oleh karena itu, perlu dilakukan perbaikan dan pemantapan. Penetapan kompetensi model ini diusahakan menjawab hal-hal berikut.

1. Isi/pengetahuan (apa yang harus diketahui tutor).

2. Keterampilan (bagaimana cara tutor melakukan sesuatu).

3. Sikap (bagaimana cara tutor berperilaku).

4. Nilai (bagaimana keyakinan tutor terhadap sesuatu).

Sistematika model ini terdiri atas komponen unit kompetensi, subkompetensi/elemen kompetensi, kriteria unjuk kerja, dan acuan penilaian. Unit-unit kompetensi tersebut disusun dan dipetakan untuk setiap bidang keahlian serta diberi kode dan nomor. Pengkodean dan penomoran unit-unit kompetensi tersebut untuk mengelompokkan sesuai kesetaraan dalam level kualifikasi.

Salah satu pola yang dapat digunakan dalam penyusunan standar kompetensi adalah mengacu pada Regional Model Competency Standard (RMCS), yang telah menjadi acuan dalam pengembangan Standar Kompetensi Kerja Nasional Indonesia (SKKNI). Berikut ini adalah contoh standar kompetensi tutor pendidikan keaksaraaan yang disusun penulis dan merupakan refleksi dari pengalaman penulis dalam penyusunan model di lapangan.

Tabel 2. Contoh standar kompetensi tutor pendidikan keaksaraan

\begin{tabular}{|c|l|l|}
\hline NO & \multicolumn{1}{|c|}{ KODE UNIT } & \multicolumn{1}{c|}{ UNIT KOMPETENSI } \\
\hline KOMPETENSI PEDAGOGI & \multicolumn{1}{|c|}{} \\
\hline 1. & PNF.TK.03.001.01 & Mengidentifikasi kebutuhan belajar \\
\hline 2. & PNF.TK.03.002.01 & Merencanakan program pembelajaran \\
\hline 3. & PNF.TK.03.003.01 & Menerapkan media belajar dalam proses pembelajaran \\
\hline 4. & PNF.TK.03.004.01 & Mengevaluasi proses pembelajaran \\
\hline KOMPETENSI KEPRIBADIAN & \multicolumn{2}{|l|}{} \\
\hline 5. & PNF.TK.03.005.01 & $\begin{array}{l}\text { Berkepribadian mantap, stabil, dewasa, arif, dan } \\
\text { bijaksana }\end{array}$ \\
\hline 6. & PNF.TK.03.006.01 & Berwibawa dan berakhlak mulia \\
\hline 7. & PNF.TK.03.007.01 & Menjadi teladan bagi peserta didik dan masyarakat \\
\hline 8. & PNF.TK.03.008.01 & Mengevaluasi kinerja sendiri secara objektif \\
\hline 9. & PNF.TK.03.009.01 & Mengembangkan diri secara mandiri dan berkelanjutan \\
\hline KOMPETENSI PROFESIONAL & \multicolumn{2}{|l}{} \\
\hline 10. & PNF.TK.03.010.01 & $\begin{array}{l}\text { Menguasai wawasan dan landasan pendidikan orang } \\
\text { dewasa (andragogi) }\end{array}$ \\
\hline 11. & PNF.TK.03.011.01 & $\begin{array}{l}\text { Menguasai wawasan dan landasan pendidikan } \\
\text { keaksaraan }\end{array}$ \\
\hline 12. & PNF.TK.03.012.01 & Menguasai strategi pembelajaran membaca \\
\hline 13. & PNF.TK.03.013.01 & Menguasai strategi pembelajaran menulis \\
\hline
\end{tabular}


Sebuah standar kompetensi idealnya dilengkapi pula dengan seperangkat bahan yang diperlukan yaitu Panduan Penyelenggaraan Diklat, Kurikulum Diklat, Modul Kompetensi Pedagogi, Modul Kompetensi Kepribadian, Modul Kompetensi Profesional, dan Modul
Kompetensi Sosial. Kurikulum, panduan, dan modul ini diharapkan dapat berfungsi sebagai bahan materi program penguatan kompetensi tutor yang dapat digunakan secara mandiri oleh perorangan, maupun secara kelompok oleh lembaga.

\section{KESIMPULAN}

Standar kompetensi tutor merupakan hal penting dalam proses pendidikan keaksaraan. Adanya standarisasi kompetensi tutor diharapkan peserta didik, yang dalam hal ini adalah warga masyarakat buta huruf, akan mendapat layanan pembelajaran yang lebih baik dan maksimal. Hal ini diperlukan karena kompetensi tutor merupakan hal yang sangat penting untuk keberhasilan sebuah proses pembelajaran.

Temuan dari meta-analytic research menunjukkan bahwa lebih dari 500.000 studi/penelitian menyatakan bahwa faktor pendidik (tutor) adalah faktor terbesar yang mempengaruhi proses belajar PD setelah faktor PD itu sendiri. Intinya ada pada kalimat, "Effective Learning" dapat berkembang secara efektif hanya jika lembaga pendidikan tersebut memiliki "Effective Teacher".

Sebagai sebuah model, kompetensi yang dibakukan merupakan kompetensi yang secara umum memang harus dikuasai oleh seorang tutor pendidikan keaksaraan. Kompetensi yang dikembangkan mengacu pada PP No. 19 Tahun 2005, Pasal 28 ayat 3 yang menyatakan bahwa kompetensi pendidik harus terdiri atas aspek kompetensi pedagogi, kompetensi kepribadian, kompetensi profesional, dan kompetensi sosial. Setelah melakukan analisis yang berkaitan dengan kompetensi pendidik, penulis berhasil mengembangkan 21 kompetensi tutor dengan puluhan elemen kompetensi dan kriteria unjuk kerjanya.

\section{DAFTAR PUSTAKA}

ACCU. (1985). Guidebook for development and production of material for neo-literate. Tokyo: Asian Cultural Center for Unesco

Coombs, P. H. \& Manzoor, A. (1984). Memerangi kemiskinan di pedesaan melalui pendidikan nonformal. Jakarta: Rajawali Press.

Direktorat Pendidikan Masyarakat. (2004). Pedoman pembelajaran pendidikan keaksaraan.Jakarta: Tidak diterbitkan.

Dixon, J. \& Tuladhar, S. (1996). Whole language: An integrated approach to reading and writing. (Action learning manual: A guide for literacy practitioners). Amherst, MA: The Center for International Education, University of Massachusetts.

Kindervatter, S. (1979). Nonformal education: As an empowering process. New York: Printers in The United Stated of America.

Kusnadi, dkk. (2005). Pendidikan keaksaraan: Filosofi, strategi, implementasi. Jakarta: Direktorat Pendidikan Masyarakat.
Payne, M. (1986). Social care in the community. London: Macmillan.

Sudjana, D. (2000). Strategi pembelajaran dalam pendidikan luar sekolah. Bandung: Falah Production.

UNESCO. (1993). Post-literacy programmes. Bangkok: UNESCO Principal Regional Office for Asia and the Pacific.

UNESCO. (1993). Continuing education: New policies and directions. Bangkok: UNESCO Principal Regional Office for Asia and the Pacific.

Victorian Institut of Teaching. (2006). Supporting provisionally registered teachers: $A$ guide to induction and mentoring and the requirements for full registration. Melbourne: Standards and Professional Learning Branch, VIT.

Yulaelawati, E. (2004). Kurikulum dan pembelajaran: Filosofi, teori, dan aplikasi. Bandung: Pakar Raya Pustaka. 